Ciência e Natura, Santa Maria, v. 37 n. 4 set-dez. 2015, p.366-384

Revista do Centro de Ciências Naturais e Exatas - UFSM

ISSN impressa: 0100-8307 ISSN on-line: 2179-460X

\title{
ciênciaenatura
}

\section{Gerenciamento de áreas de risco em cidades brasileiras: projetos e programas}

\author{
Management of risk areas in Brazilian cities: projects and programs \\ Edson Luis de Almeida Oliveira ${ }^{1}$, Luis Eduardo de Souza Robaina² \\ ${ }^{1}$ Instituto Federal Sul-rio-grandense, RS, Brasil \\ 2 Universidade Federal de Santa Maria, RS, Brasil
}

\section{Resumo}

Os episódios da dinâmica superficial causadores de risco no território brasileiro, tais como os deslizamentos, as inundações e as corridas de massa, marcaram a geografia histórica dos desastres no Brasil. Estes eventos, que provocaram perdas significativas para a sociedade, fizeram com que estratégias de gestão e gerenciamento fossem colocadas em prática por órgãos públicos municipais, principalmente, nos grandes aglomerados urbanos. Este artigo aborda as questões relativas aos programas e projetos, relacionados ao gerenciamento de áreas de risco, no ambiente urbano, em algumas cidades brasileiras, são elas: Rio de Janeiro, Recife, Belo Horizonte, São Paulo (região metropolitana e Santos) e para as cidades localizadas no vale do rio Itajaí em Santa Catarina. Estas cidades desenvolveram projetos e programas associados ao gerenciamento de risco que dão lugar às ações anteriormente prioritárias de agir após o desastre, fato que implicava em uma imobilidade por parte das comunidades atingidas e que acabava criando uma cultura assistencialista. A mudança que começa a ocorrer indica que a prevenção começa a ser prioritária no tratamento das áreas de risco no espaço urbano, e as comunidades inseridas no processo de construção de um espaço mais digno e seguro dentro da cidade.

Palavras-chave: Gerenciamento, Áreas de risco, Projetos e programas.

\section{ABSTRACT}

The episodes of the surface dynamics that cause risk in Brazilian territory, such as landslides, floods and debris flows, marked the historical geography of disasters in Brazil. These events that caused significant losses to society have made management strategies to be put into practice by local government, especially in large urban areas. This article approaches issues related to the programs and projects related to the management of risk areas in the urban environment in some Brazilian cities such as: Rio de Janeiro, Recife, Belo Horizonte, Sao Paulo (Santos and metropolitan region) and cities located in the Itajai river valley in Santa Catarina. These cities have developed projects and programs associated to risk management that give the place earlier priority actions: to act after the disaster - a fact which implied no reaction from the affected communities and that ended up creating a welfare aid culture programs. The change that begins to occur indicates that prevention starts to be a priority in the treatment of high-risk areas in the urban space, and that the communities are part in the construction of a more dignified and safe space in the city

Keywords: Management, risk areas, projects and programs. 


\section{Introdução}

No Brasil, país localizado na periferia do mundo capitalista, as perdas e danos provocados por processos da dinâmica superficial fazem parte da história dos desastres em nosso território, como os que ocorreram em 1928 em Monte Serrat (Santos-SP), provocando mais de 80 mortes; o acidente que aconteceu em janeiro de 1967 na Serra das Araras, no Rio de Janeiro (1200 pessoas morreram), assim como a destruição de dezenas de casas, várias rodovias avariadas e a destruição de uma usina hidrelétrica. O desastre no Vale do rio Itajaí em Santa Catarina, em novembro de 2008, também provocou a morte de dezenas de pessoas e milhões em danos ao patrimônio público e privado.

Entretanto, somente após as fortes chuvas que desencadearam um dos maiores desastres da história recente do país, e levou ao óbito mais de 900 pessoas na região serrana do Rio de Janeiro, em 2011, que houve uma profunda reorientação na esfera da Defesa Civil em âmbito federal, com a Lei n. 12.608, de 10 de abril de 2012, que instituiu a Política Nacional de Proteção e Defesa Civil (PNPDEC). Essa nova legislação estabelece que atividades de gestão e gerenciamento de áreas risco apresentam um papel importante no equacionamento das áreas de risco em nossos municípios.

Os episódios de deslizamentos, de inundações e corridas de massa que marcaram a geografia histórica dos desastres no Brasil, fizeram com que estratégias de gestão e gerenciamento fossem colocadas em prática por órgãos públicos municipais, principalmente, nos grandes aglomerados urbanos. Este artigo aborda as questões relativas aos programas e projetos, relacionados ao gerenciamento de áreas de risco, no ambiente urbano, em algumas cidades brasileiras, são elas: Rio de Janeiro, Recife, Belo Horizonte, São Paulo (região metropolitana e Santos) e para as cidades localizadas no vale do rio Itajaí em Santa Catarina.

\section{Definição de Risco}

O planeta Terra possui uma dinâmica própria, resultado de processos endógenos (associados ao tectonismo e vulcanismo) e processos exógenos (vinculados à atmosfera e hidrosfera) e recentemente, na história evolutiva, o homem como um ser, vivendo em sociedade, capaz de modificar profundamente a paisagem.

A noção do risco só pode ser compreendida quando existe a probabilidade de um determinado evento provocar danos e perdas em sua inter-relação com a sociedade e seus bens materiais. De acordo com Marandola Jr. \& Hogan (2004, p.100), “Risco (risk) é utilizado pelos geógrafos como uma situação, que está no futuro e que traz a incerteza e a insegurança".

Para que exista o risco, é necessário a existência de um grupo social com um certo grau de vulnerabilidade. Sendo assim, o risco como categoria de análise é uma construção humana.

O risco é derivado da relação dinâmica e dialética entre as ameaças físicas e as múltiplas vulnerabilidades de uma sociedade ou de um componente particular desta (LAVELL, 2003). Com a presença da sociedade e suas construções em todo planeta, os eventos naturais, associados a diversos graus de vulnerabilidade, vem provocando grandes perdas econômicas e, não raramente, a perda de vidas.

As áreas de risco na sociedade dos países periféricos constituem-se em um problema sério, principalmente, para os grupos sociais excluídos e segregados no espaço 
urbano. Por apresentarem um acesso diferencial à renda, são impelidos a ocuparem terrenos que apresentam grande suscetibilidade aos processos da dinâmica superficial. Conforme destaca Coelho (2001, p.28), "as cidades historicamente localizaram-se às margens dos rios. A incidência das inundações motivou as classes médias e altas a se afastarem das áreas urbanas delimitadas como áreas de risco. As inundações continuam a vitimar as classes pobres".

Para Nogueira (2006, p. 29), "o termo risco indica a probabilidade de ocorrência de algum dano a uma população (pessoas ou bens materiais). É uma condição potencial de ocorrência de um acidente", sendo expresso pela seguinte equação: $\mathbf{R}=\mathbf{P}(\mathbf{f A}){ }^{*} \mathbf{C}(\mathbf{f V})^{*} \mathbf{g}-\mathbf{1}$,

[...] onde risco $\mathrm{R}$ representa a probabilidade $\mathrm{P}$ de ocorrer um fenômeno físico (ou perigo) A, em local e intervalo de tempo específicos e com características determinadas (localização, dimensões, processos e materiais envolvidos, velocidade e trajetória); causando conseqüências C (às pessoas, bens e/ou ao ambiente), em função da vulnerabilidade $\mathrm{V}$ dos elementos expostos; podendo ser modificado pelo grau de gerenciamento g (NOGUEIRA,2006,p.29).

Em publicação da UNISDR (2009, p. 29) o risco (riesgo) é definido como "la combinación del a probabilidadde que se produzca um evento y SUS consecuencias negativas."

Assim podemos definir o risco como a probabilidade de que estruturas construídas, atividades produtivas, assim como a população possam sofrer algum dano ou perda em função de um processo da geodinâmica, quando essas situações se materializam no espaço temos um acidente, que dependendo da proporção e da intensidade das perdas e danos pode caracterizar um desastre.

\section{Gestão e gerenciamento de áreas de risco}

A gestão de risco deve compreender atividades de planejamento, organização e participação dos atores envolvidos, ou seja, os órgãos estatais responsáveis por ações de planejamento, instituições públicas de ensino e pesquisa e a sociedade civil organizada, por meio de ONGs e associações comunitárias.

Estratégias de gestão devem conter ações no sentido de incrementar a capacidade da comunidade para transformar as condições perigosas e reduzir a vulnerabilidade, englobando estratégias mais amplas do que somente assistência e a recuperação pósdesastre.

Conforme a terminologia utilizada pela UNISDR (2009), a gestão do risco de desastre é um processo sistemático de utilizar diretrizes administrativas, organização, habilidades e capacidades operacionais para executar políticas e fortalecer as capacidades de enfrentamento, com a finalidade de reduzir o impacto adverso de ameaças ${ }^{1}$ naturais e a possibilidade de que ocorra um desastre.

Souza \& Rodrigues (2004) e Souza (2004) afirmam que gestão e planejamento não são termos "intercambiáveis", pois estes referem-se a atividades diferentes por possuírem referenciais temporais distintos.

O que difere a gestão do planejamento é que a gestão constitui-se em uma atividade que se associa ao presente, uma situação imediata dentro de uma determinada conjuntura (Souza \& Rodrigues, 2004).

\footnotetext{
1 No documento intitulado "Terminologia sobre a redução de risco de desastre", a UNISDR considera o termo ameaça como sinônimo para o termo perigo.
} 
Assim, um determinado espaço urbano é tanto objeto do planejamento, seja ele qual for, quanto alvo da gestão, é a escala temporal que os difere de acordo com os autores citados. Para Souza (2004, p.46), "o planejamento é a preparação para a gestão futura", assim, a gestão, pelo menos em parte, é a efetivação das atividades de planejamento.

Conforme Bitar (2010), os termos "gestão", "gerenciamento", administração" e "manejo ambiental" são correlatos ao termo "gestão ambiental" encontrados na literatura técnica relacionada. E eles mudam "[...] de acordo com o campo do conhecimento técnicocientífico do qual se originam e fundamentam os métodos e técnicas correspondentes, ou com o setor econômico em que se aplicam" (BITAR, 2010, p.91).

Desta forma, para Nogueira (2002, p.13), “o gerenciamento de riscos é um dos instrumentos de gestão urbana que ganha destaque neste momento de intenso debate sobre as alternativas para a crise das cidades". Associado com outras políticas públicas para o ambiente urbano, pode ser de grande utilidade para reduzir os níveis atuais de perdas em função de acidentes e desagregação socioespacial. $O$ autor afirma que o gerenciamento de riscos urbanos requer uma postura transdisciplinar, pois, na atualidade e neste campo específico, nenhum profissional pode restringir-se apenas a sua própria formação acadêmica para desenvolver suas atividades.

Gerenciamento, na concepção aqui adotada, envolve o conjunto de ações de organização e operação institucional para o tratamento de situações de risco existentes, no âmbito da competência e atribuição do órgão público que o executa. A participação da sociedade civil em fóruns responsáveis por realizar atividades de planejamento e gestão é de fundamental importância para uma real eficiência das medidas adotadas.

Conforme Rebelo (2008), em primeiro lugar, a gestão do risco exige o conhecimento do processo potencialmente perigoso, como também de todo o trabalho humano que o possa intensificar. Em seguida, exige o conhecimento de como a população está distribuída pela área a ser atingida, potencialmente, pelo desencadear de um processo, ou seja, o conhecimento do grau de exposição ao processo (op. cit).

Compreende-se que o gerenciamento de risco constitui-se em uma atividade da gestão ambiental urbana que procura, através de atividades sistemáticas, equacionar os cenários de risco em nossas cidades. Assim, esse gerenciamento envolve atividades de diagnóstico, mapeamento e hierarquização dos problemas, com o intuito de estruturar atividades de redução de risco e prevenção que reduzam as perdas. A gestão do risco deve ter os seguintes pressupostos:

EVITAR a formação de áreas de risco (preventivas)

- Mapeamento e zoneamentos dos riscos

- controle efetivo do uso do solo (plano diretor)

REDUZIR/MINIMIZAR os problemas (remediadoras)

- agindo sobre o processo

- agindo sobre a conseqüência

CONVIVER com os problemas (emergenciais)

- planos de contingência (PPDC)

\section{Para isso, as ações se dividem em: \\ ESTRUTURAIS}

- Obras de contenção, drenagem, proteção superficial

- Reurbanização

- Relocação de moradias e população 


\section{NÃO-ESTRUTURAIS}

- Cartas geotécnicas e de risco

- Planos Preventivos de Defesa Civil

- Educação e capacitação

- Planejamento urbano

\section{Exemplos de Ações não-estruturais no Gerenciamento de Risco de Desastres em Cidades Brasileiras}

Em virtude do histórico dos eventos e acidentes ocorridos no espaço urbano de algumas cidades brasileiras, projetos e programas foram criados com o intuito reduzir as perdas e danos desencadeados pelos processos da dinâmica superficial, a seguir apresentase alguns exemplos.

\subsection{Rio de Janeiro}

As atividades efetivas de gestão de risco, na cidade do Rio de Janeiro, começaram após os eventos catastróficos de 1966. Este desastre fez com que o governo do então estado da Guanabara criasse um órgão específico para o gerenciamento de riscos de escorregamentos na cidade, o Instituto de Geotécnica, atual fundação GEO-RIO, órgão da Secretaria Municipal de Obras.

Os episódios de deslizamentos e de inundações que marcam a história da cidade do Rio de Janeiro levaram à criação de um sistema de alerta, que vai ao encontro das atuais políticas de gerenciamento de risco.

O sistema Alerta Rio ${ }^{2}$ (Sistema de Alerta de Chuvas Intensas e de Deslizamentos em Encostas da Cidade do Rio de Janeiro) foi criado em 25 de Setembro de 1996, pelo Decreto №15142, e tem por objetivo o monitoramento das condições meteorológicas em tempo integral, possibilitando a emissão de boletins de alerta de chuvas e escorregamento. Esse sistema realiza a transmissão de dados para uma central a cada 15 minutos (WALDHEIM, 2006). Os alertas são emitidos de acordo com a seguinte metodologia: para divulgação da mudança dos estágios de chuvas intensas e probabilidade de escorregamentos, são emitidos boletins para órgãos públicos municipais e para rádios e emissoras de TVs da cidade do Rio de Janeiro. Atualmente, o sistema Alerta Rio mantém seu objetivo inicial, ou seja, o alerta de escorregamentos para a cidade do Rio de Janeiro.

Apesar das ações de gerenciamento citadas, a história recente comprova que ainda existe muito a ser feito em termos de gestão e gerenciamento de riscos para o estado do Rio de Janeiro, especialmente no que se refere à atualização dos mapas de risco, medidas estruturais localizadas e amplas como reassentamento de moradias.

\subsection{Gerenciamento de Risco em BeloHorizonte/MG}

Conforme Prudente \& Reis (2009, p.1), a ocupação da cidade de Belo Horizonte

[...] foi concebida de forma planejada, inicialmente o projeto pretendia concentrar a população dentro da área da avenida do Contorno, entretanto, o crescimento

\footnotetext{
${ }^{2}$ Os dados fornecidos pelo Alerta Rio podem ser consultados em : http://alertario.rio.ri.gov.br/
} 
acelerado fez com que a população de baixa renda habitasse áreas impróprias para ocupação, como beira de córregos, encostas de declives acentuados.

Segundo Xavier et al.(1996) apud Prudente \& Reis(2009), os riscos mais frequentes no município de Belo Horizonte estão associados às inundações, erosões, desmoronamentos e deslizamentos de encostas.

No ano de 1983 foram registrados 722,5mm de chuva, 426mm acima da média histórica. Ao longo do mês, as chuvas favoreceram a ocorrência de deslizamentos e inundações, que resultaram em danos humanos e materiais à população (PEREIRA \& REIS, 2009).

Em 1979, foi registrado um índice pluviométrico de $769 \mathrm{~mm}$ de chuvas que atingiram Belo Horizonte causando uma situação de calamidade pública (PEREIRA\&REIS, 2009 , p.6). Segundo os autores, foram mais de 3500 pessoas desabrigadas e 300 mortos em todo o estado de Minas Gerais, sendo 16 na capital.

A estação chuvosa de 2002/2003, que provocou a morte de 16 pessoas e, no mesmo período em 2003/2004 (REIS et al, 2004).

Nos eventos que atingiram o estado de Minas Gerais no período chuvoso do verão de 2011/12, de acordo com o boletim №53 da Defesa Civil de Minas Gerais do dia 22/02/2012, 234 municípios decretaram situação de emergência, 34 comunicaram à Defesa Civil terem sido atingidos por evento adverso, mas não decretaram situação de emergência, 19 óbitos foram confirmados, 245 feridos, 9.507 pessoas desabrigadas e 103.753 desalojadas. Conforme a Defesa Civil-MG, em todo o estado, 3.538.274 pessoas foram afetadas.

Com esse histórico, é desenvolvida em Belo Horizonte uma das experiências mais significativas sobre gestão de áreas de risco em municípios brasileiros, o Programa Estrutural em Áreas de Risco - PEAR.

Desenvolvido pela URBEL (Companhia Urbanizadora de Belo Horizonte ), o PEAR surgiu em 1993, segundo Pereira (2007, p.12), e constitui-se em um "programa de assistência técnica às famílias moradoras em áreas de risco, de caráter contínuo, com ações nas áreas física e social".

Ainda conforme o autor (op.cit, p. 13), o PEAR é um

\footnotetext{
Programa da Política de Habitação de Belo Horizonte que visa diagnosticar, prevenir e minimizar situações de risco geológico. Possui como premissa a convivência com o risco, mediante ações e procedimentos de redução do risco, através da diminuição tanto da probabilidade quanto dos danos associados a acidentes. Foca a atenção no gerenciamento do problema, sem deixar de investir em intervenções físicas.
}

O modelo de gestão adotado na execução do PEAR-BH consiste em uma política centralizada com ações regionalizadas, na qual se realizam vistorias individualizadas por equipes multidisciplinares, conforme Pereira (2007, p.14), o PEAR estrutura-se através de uma "gestão compartilhada e de proximidade; Gestão articulada com outros órgãos municipais e estaduais - GEAR.; Investimento em ferramentas de planejamento urbano/ análise dos resultados: Diagnóstico das áreas de risco, PMRR, balanços semestrais discutidos com a comunidade".

Sendo que em 1994/95 foi realizado o 1ํo Diagnóstico de Risco Geológico da cidade de Belo Horizonte, em 2005, foi elaborado o Plano Municipal de Redução de Risco - PMRR, com $80 \%$ dos recursos financiados pelo Ministério das Cidades e $20 \%$ com recursos da 
Prefeitura Municipal de Belo Horizonte, foram mapeadas 195 vilas e constataram-se 5.372 moradias em risco alto e muito alto de escorregamento e solapamento, sem contabilizar as inundações (PEREIRA, 2007).

A gestão de risco em Belo Horizonte acontece de forma contínua e intensifica-se nos períodos chuvosos, com a realização de vistorias e intervenções pontuais quando necessário, prestando assistência técnica e social às famílias inseridas em áreas de risco.

O Programa Estrutural em Áreas de Risco tem entre seus principais objetivos: diagnosticar, controlar, prevenir e minimizar as situações de risco na cidade. É um dos mais reconhecidos no Brasil, diminuindo a vulnerabilidade das populações. Entretanto, como acontece com outras cidades, a questão estrutural mais importante, que está ligada à distribuição efetiva da renda, está longe de ser resolvida, acarretando novos desastres todos os anos.

\subsection{Gerenciamento de Risco em São Paulo (Região Metropolitana e Santos)}

Colocando em questão o problema dos escorregamentos no território brasileiro, Augusto Filho (1994, p.4) destaca a urbanização e "o empobrecimento geral da população, que contribuem para a instalação de situações de risco nas cidades, a partir da ocupação de áreas naturalmente suscetíveis a escorregamentos sem os critérios técnicos mínimos recomentados".

Na região serrana do estado de São Paulo, os acidentes associados à instabilização das vertentes são comuns e destacam-se principalmente após a segunda metade do século XX, quando o estado de São Paulo passa por um forte processo de urbanização, vinculado principalmente ao crescimento econômico do setor industrial e coincide com a fase de grande crescimento da população urbana brasileira.

Conforme destacam Amaral \& Fuck (1973) apud Instituto de Pesquisas Tecnológicas - IPT (2002), o evento de "corrida de lama", que atingiu a Vila Albertina em Campos do Jordão em 1972, é um dos eventos significativos, o qual demonstra esse processo de urbanização precária

\footnotetext{
No dia 18 de agosto de 1972, às 8:15h da manhã, verificou-se um deslizamento de cerca de 70.000 metros cúbicos de lama altamente aquosa e rica em matéria orgânica de origem vegetal, numa vila operária chamada Vila Albertina, situada quase $2 \mathrm{~km}$ a sudoeste da entrada principal para Campos do Jordão, município do Estado de São Paulo. Amaral \& Fuck (1973) apud IPT (2002, s/p)
}

Nove anos depois, segundo IPT (2002), o acidente provocado pelos movimentos gravitacionais de massa que ocorreram em Campos do Jordão no início do ano de 2000 pode ser considerado como um dos mais impressionantes já ocorridos em áreas urbanas no Brasil. O evento que no período crítico de chuvas, entre o dia 31/12/99 e o dia 04/01/00, acumulou um total pluviométrico de $453,2 \mathrm{~mm}$ atingiu bairros populares e nobres da cidade, mas também se estendeu para além do limite urbano, atingindo ainda taludes de rodovias, estradas de terra e vertentes da região rural do município (op.cit.). Esse evento causou a morte de 10 pessoas e a destruição de muitas moradias (OGURA; SILVA \& VIEIRA, 2004).

Os acidentes que ocorreram em 2000 na cidade Campos de Jordão e região levaram o Governo do Estado de São Paulo a estender a área de atuação do Plano Preventivo de Defesa Civil - PPDC para a região do Vale do Paraíba e Serra da Mantiqueira (IPT, 2002). 
Após esse desastre, o governo municipal contratou o IPT para realizar trabalhos de mapeamento de risco de processos de escorregamentos

com objetivo geral, a produção de subsídios técnicos para a montagem de um Plano Municipal de Gerenciamento de Áreas de Risco de Escorregamentos. Esse plano nortearia as ações municipais de controle da ocupação de encostas e de recuperação e melhoria das condições de habitação das vilas operárias gravemente atingidas pelos acidentes de 2000. (OGURA; SILVA \& VIEIRA, 2004, p. 46)

A cidade de São Paulo é o maior centro urbano do país e também o polo gravitacional da economia brasileira. Caracterizada por um rápido crescimento populacional após a década de 1970, a cidade enfrenta hoje sérios problemas associados à ocupação de áreas susceptíveis aos processos da dinâmica superficial.

Conforme Chakarian (2008), até meados da década de 1970, a área urbana do município de São Paulo concentrava-se em terrenos da bacia sedimentar, onde, pela característica de relevo pouco íngreme, não ocasionava maiores riscos. Citando Freire (2006), a autora relata que esse quadro se altera com a substituição do modelo de crescimento urbano, o qual anteriormente era baseado em padrões precários, contando com territórios extensivos e a autoconstrução da casa própria, passando por um processo de favelização do espaço urbano (CHAKARIAN, 2008).

Conforme PREFEITURA DE SÃO PAULO (s/d), entre 1930 e 1980, a mancha urbana paulistana foi quintuplicada, passando de $355 \mathrm{~km}^{2}$ para $1370 \mathrm{~km}^{2}$. A expansão urbana da cidade ocorre de forma a atender o interesse do setor imobiliário, pois "preservando vazios entre novos loteamentos e os anteriores, já dotados de infraestrutura, de modo a valorizá-los através da implantação de melhorias públicas para atender o ponto extremo loteado" (op.cit.).

De acordo com Taschner (2000) e Marques et al. (2003), o número de habitantes em ocupações informais cresceu, na Grande São Paulo, de forma significativa a partir da década de 1980. “Na cidade de São Paulo, mais de 30\% dos moradores, ou seja, cerca de 3 milhões de pessoas vivem em condições de alguma precariedade urbana" (SEHAB-SP, 2010, p.10). Os moradores dessas localidades "vivem em áreas precárias conhecidas como favelas, cortiços ou loteamentos irregulares. Desvinculadas da chamada "cidade formal" são exemplos inequívocos da desigualdade no espaço urbano" (SEHAB-SP, 2010, p.10).

Kowarick (2009), refletindo sobre o processo de construção da moradia própria, destaca que, em função do elevado custo do preço da terra na capital paulista, o qual subiu em média mais de 150\% no período de 1959 e 1980, a autoconstrução da moradia tornou-se mais cara na capital, "o que fez o número de moradores em favelas crescer rapidamente a partir de 1980, quando passa a ocorrer sua urbanização"(KOWARICK, 2009, p.170).

Destacando que a expansão da periferia na Região Metropolitana de São Paulo

ocorreu principalmente a partir da década de 1970 com a abertura de inúmeros loteamentos, muitos deles "clandestinos", ou seja, projetados e vendidos sem a aprovação da municipalidade e desrespeitando a legislação de parcelamento e uso do solo (PASTERNAK \& BOGUS, 2004, p.84).

Com o crescimento rápido da cidade aliado à ocupação de áreas não adequadas, em São Paulo, intensificam-se os problemas relacionados com as áreas de risco. De acordo com Chakarian (2008) 


\begin{abstract}
O gerenciamento de riscos durante os períodos chuvosos, no município, era voltado para os impactos gerados no trânsito, causados por inundações na região do centro expandido da capital paulistana. As análises e avaliações alcançavam, no máximo, até as marginais dos rios Tietê e Pinheiros (op.cit., p. 25).
\end{abstract}

A autora afirma que, somente a partir da década de 1980, começam a ser discutidas questões relativas à identificação das áreas de risco no município de São Paulo, inicialmente com uma abordagem de um sistema de controle para realizar a remoção da população e realizar intervenções nessas áreas. “Já no final dessa década, as áreas de risco já não estavam somente localizadas nas áreas de expansão da cidade. As invasões de terrenos públicos também geraram ocupações de risco" (CHAKARIAN, 2008, p. 26).

Refletindo sobre o histórico da ocupação urbana de São Paulo e a produção das áreas de risco, constata-se que, a partir da década de 1990, os acidentes associados aos escorregamentos tornaram-se mais frequentes e menos localizados (PREFEITURA DE SÃO PAULO, s/d).

Conforme Chakarian (2008, p. 26), “em junho de 1983, foi feito o primeiro registro de evento calamitoso envolvendo instabilização de taludes". A autora destaca que, em 1984, o IPT elaborou a Carta Geotécnica da Grande São Paulo, que tinha por objetivo identificar os processos naturais e orientar a expansão urbana. Em 1986, foi elaborada também, por técnicos do IPT, a Carta Geotécnica do município de São Paulo e, em 1985, junto com a Empresa Metropolitana de Planejamento da Grande São Paulo (EMPLASA), foi elaborada a carta de Aptidão Física ao Assentamento Urbano.

Em outubro de 1989, ocorreu um deslizamento de terra na favela Nova República, provocando a morte de 14 pessoas. A favela Nova República era um aterro de porte grande que sofreu uma ruptura em um talude de aproximadamente 40 metros de altura (op.cit). Constata-se que esse evento foi um marco significativo que, posteriormente, orientou a política de gerenciamento de áreas de risco no município de São Paulo, visto que o Ministério Público na época denunciou a prefeitura como responsável pelo acidente, sendo, inclusive, funcionários públicos indiciados criminalmente por esse evento. Isso levou à inclusão na Lei Orgânica municipal de um inciso onde cabe ao município gerenciar as áreas de risco.

Dessa forma, a Lei Orgânica do Município de São Paulo (1990, p.40), atualizada até a Emenda no 34, de 27/4/2011, traz no capítulo relativo à política urbana, um inciso específico sobre o papel da Prefeitura com relação ao gerenciamento de áreas de risco

O município de São Paulo, no cenário brasileiro atual, relativo a políticas de gerenciamento de risco, apresenta alguns avanços. Em 2010, um estudo realizado pela prefeitura e o IPT denominado "Análise e mapeamento de riscos associados a escorregamentos em áreas de encostas e a solapamentos de margens de córregos" considerou todo o território do município;

Segundo a PREFEITURA DE SÃO PAULO (2011, p. 2), esse foi o maior mapeamento de áreas de risco do Brasil, cobrindo a totalidade das áreas vulneráveis da Cidade de São Paulo; adequação e aperfeiçoamento das metodologias utilizadas anteriormente; verificação da eficácia das intervenções implantadas nos últimos 05 anos; primeiro banco de dados completo e multidisciplinar focado na população moradora de áreas precárias, com informações socioeconômicas, urbanísticas e geográficas. No total, 
foram mapeadas 407 áreas em 26 Subprefeituras, sendo 1.179 setores avaliados, destes 607 apresentaram risco alto e muito alto; 572 de risco médio e baixo.

A Prefeitura de São Paulo, através de portaria, anualmente decreta para o período de fortes chuvas o "Plano Preventivo de Defesa Civil - Chuvas de Verão", o monitoramento e a previsão meteorológica ficam a cargo do CGE - Centro de Gerenciamento de Emergências.

Assim, a maior cidade do país procura com essas medidas criar, de forma sistêmica, políticas públicas e sistemas de gerenciamento que objetivem, senão erradicar os riscos urbanos, melhorar os mecanismos de prevenção frente aos processos naturais desencadeadores de desastres.

Um outro exemplo fora da região metropolitana é a cidade de Santos, no litoral paulista, que tem um histórico de acidentes associados aos movimentos de massa, como o que ocorreu em 1928 em Monte Serrat, provocando mais de 80 mortes (NOGUEIRA, 2002).

A prefeitura de Santos criou por decreto o "Grupo Executivo de Morros", em 1989, um serviço voltado exclusivamente para o enfrentamento dos riscos associados a escorregamentos, ação pioneira para enfrentamento dos processos da dinâmica superficial causadores de desastres associados à ocupação das vertentes. Em 1993, esse grupo tornouse uma administração regional (Administração Regional dos Morros), contando com orçamento próprio (op. cit). Em 1996, chegou a contar com uma equipe de técnicos de caráter multidisciplinar, totalizando 30 pessoas e mais 120 trabalhadores operacionais, responsáveis pela redução do risco geológico, bem como por colocar em operação o Plano Preventivo de Defesa Civil (op.cit).

Conforme Nogueira (2002), em 1997, ocorreu uma modificação na orientação política da administração municipal, o que provocou um esvaziamento técnico das atividades desse órgão, em 1998, quando de uma reforma administrativa, a Administração Regional dos Morros foi extinta.

Embora a cidade de Santos possua um PMRR, elaborado em 2005 e revisado em 2012 pelo IPT, com o qual foram analisadas 22 áreas de risco e 104 setores foram identificados, abrangendo 11,4 mil moradias (IPT, 2012), este ainda carece de implantação efetiva (MPSP, 2010).

Essas ações demonstram que ações de prevenção de riscos, como o exemplo de Santos, sofreram com as descontinuidades de políticas públicas criadas no passado e que a maior cidade do país procura estabelecer estratégias de prevenção, um grande desafio pela complexidade do seu espaço urbano.

\subsection{Gerenciamento de Risco na Região Metropolitana do Recife}

A ocupação das vertentes é um dos principais cenários de risco na cidade de Recife em Pernambuco. Em 1994, a Prefeitura instituiu o programa Parceria nos Morros, sob a gerência da Empresa de Urbanização do Recife - URB, “órgão da administração indireta municipal, é voltado à atuação em áreas de risco situadas em terrenos particulares" (PRADO, 2006, p.138).

Conforme Alheiros et al (2003, p. 28), o processo de ocupação dos morros do Recife faz parte "da história da construção da cidade pelos segmentos pobres que, desde as origens coloniais, se deu em terrenos pouco propícios à edificação".

Alheiros et al (op.cit.) ressaltam que a perspectiva de ver repetidos os acidentes que aconteceram no inverno de 1996, os quais desabrigaram um grande número de famílias na 
região metropolitana do Recife, inclusive fazendo vítimas fatais, levou o Prefeito de Camaragibe, Paulo Santana, a fazer um alerta, em abril de 1997, ao "propor a inclusão do tema Morros e Encostas, na pauta de discussão dos problemas comuns aos municípios da região metropolitana, como "uma questão de direito à vida" (ALHEIROS et al, 2003, p. 11).

Alheiros (1998) realizou sua tese de doutorado sobre os escorregamentos que afetam a região metropolitana do Recife, a autora relata alguns acidentes importantes que provocaram grandes perdas econômicas, bem como a morte de um número significativo de habitantes, como os escorregamentos que atingiram a região metropolitana do Recife, em 1984, ocasionando 12 mortes; o que atingiu a cidade do Recife em 1990, provocando 39 óbitos e o de 1996, provocando a morte de 42 pessoas e a destruição de dezenas de casas (op. cit., p.77).

Conforme Prado (2006), o programa Parceria nos Morros tinha como objetivo inicial prover formas alternativas de contenção das encostas, bem como estimular uma maior participação dos beneficiários no planejamento e na execução das obras.

Em 1998, o Conselho de Desenvolvimento da Região Metropolitana do Recife CONDERM - estabeleceu o controle urbano e a ocupação dos morros e encostas como um dos temas prioritários da agenda para aquele exercício (PRADO, 2006). No ano de 2000, foi criado o programa Viva o Morro, após uma série de reuniões entre os órgãos públicos municipais, estaduais e federais, bem como órgãos ligados à sociedade civil, o objetivo do programa é desenvolver ações em áreas de risco urbano (op.cit.).

Alheiros et al (2003, p.45), referindo-se às ocupações espontâneas em áreas de morros, tão características da Região Metropolitana do Recife, apontam as principais características do modo de ocupação espontânea, a saber:

- ocupações desordenadas através de um processo de invasão;

- remoção da vegetação natural;

- corte da barreira para criar terreno para os acessos e as casas;

- aumento do talude do corte para ampliação do terreno;

- lançamento de aterro não compactado (bota-fora) na borda da encosta;

- acessos com redes viárias irregulares;

- baixo padrão construtivo das moradias;

- ausência de calhas, biqueiras e impermeabilização no entorno da casa;

- ausência de canaletas para a drenagem das águas servidas e pluviais;

- fossa localizada no topo da face da encosta;

- lixo jogado sobre o talude dificultando a drenagem natural;

- lixo jogado nas canaletas obstruindo a drenagem formal;

- árvores no talude de corte e na crista da encosta.

Essas características de ocupação espontânea marcam a paisagem de tantas outras cidades brasileiras que convivem com as áreas de risco de escorregamentos, ou seja, a necessidade de criar um lugar para viver acaba consolidando um tipo de ocupação desordenada que é um dos aspectos fundamentais no desequilíbrio das encostas.

Frente a essa realidade, em 2001, a prefeitura do Recife criou o programa "Guarda Chuva", que possui atuação nos seguintes eixos: controle urbano, defesa civil permanente, ações integradas de pequeno porte, urbanização (obras estruturadoras), política habitacional e mudança de cultura. Esse programa tem como objetivo principal "atuar permanentemente nos morros e nas planícies, monitorar as áreas de risco, realizar obras, 
limpeza de canais e drenagens e desenvolver ações nas áreas de habitação e saneamento" (PRADO, 2006, p.138).

$\mathrm{O}$ autor ressalta os principais méritos e aspectos inovadores do programa

1- É muito importante perceber que o programa conseguiu superar o padrão emergencial de atuação em áreas de risco, adotando um padrão de atuação preventiva.

2- Uma diretriz importante do programa é o uso de soluções técnicas nãotradicionais, de baixo custo, fácil execução e manutenção. Isso permite não só diminuir os custos das intervenções, mas também capacitar a própria população beneficiada como mão-de-obra.

3- Um efeito extremamente positivo do tipo de obra adotado, que permite que sejam executadas pela própria população beneficiada, é praticamente não existir depredação das obras finalizadas, já que os membros da comunidade que as realizam são também os seus maiores beneficiários.

4- Outro aspecto importante, e exclusivo do programa Parceria nos Morros, é a existência de unidades descentralizadas de atendimento: as Estações nos Morros.

5- A participação da comunidade, ponto central do programa, é um fato concreto.

6- Finalmente, ao analisar o custo-benefício do projeto, podemos considerar que as soluções técnicas adotadas possuem um custo relativamente baixo. Uma conta simples mostra que o custo médio por intervenção está em pouco menos de R\$9.000. (Prado, 2006, p. 140, 141e 142)

Alheiros et al (2003) evidenciam que exite sinais de mudança no modo de tratar os morros na Região Metropolitana do Recife. Conforme os autores, essa mudança está ocorrendo a partir de dois polos

[...] a qualificação da Defesa Civil, parceira tradicional do setor de Obras nos morros, e a preocupação que vem se difundindo entre os gestores municipais e de setores do Estado de romper a ação pontual e emergencial na época de chuva, além da implantação de novas práticas de Planejamento, a exemplo do Orçamento Participativo, propiciando um debate mais amplo sobre prioridades e ações (op. cit, p.109).

O Programa Viva o Morro constitui-se na atualidade em uma das experiências mais exitosas no âmbito do Gerenciamento de áreas de risco em encostas, pois, além de ações voltadas para a recuperação, o reordenamento e a estabilização das vertentes dos morros ocupadas de forma precária, é um programa no qual a participação da comunidade acontece de forma significativa, e as ações se desenvolvem no intuito de conviver com o risco e orientar a população sobre as técnicas construtivas mais adequadas de serem executadas no meio físico onde vivem ${ }^{3}$.

Estas ações desenvolvidas em Recife, de forma articulada e integrada com os moradores das áreas de risco, vão ao encontro das atuais políticas públicas que propõem estratégias de prevenção e de gestão e gerenciamento de áreas de risco.

3 No site do Governo do Estado de Pernambuco é possível ter acesso aos materiais produzidos pelo Programa Viva o Morro. http://200.238.107.83/web/condepe-fidem/apresentacao12 


\subsection{Gerenciamento de Risco em Santa Catariana}

Os episódios que aconteceram no Vale do rio Itajaí em Santa Catarina, em novembro de 2008, demonstram a grande vulnerabilidade dos habitantes daquela região. $\mathrm{O}$ evento provocou escorregamentos, enxurradas e inundações, o que fez com que 14 municípios decretassem estado de calamidade pública e 63 a decretar situação de emergência (MATTEDI et al, 2009).

Durante as últimas décadas, Santa Catarina tem sido o cenário de vários desastres naturais, principalmente em sua vertente atlântica. As "chuvas intensas afetaram o estado de Santa Catarina desde o dia 22 até 24 de Novembro de 2008, causando severas inundações e deslizamentos que afetaram 1.5 milhões de pessoas" (MARENGO, 2009, p.2).

O autor afirma que, em muitas regiões do sul da América do Sul, onde encontramse registros climáticos de vários anos, "têm-se observado um aumento na frequência de eventos de chuva intensa, que em parte explicam o número crescente de desastres naturais como deslizamentos de terras e inundações, responsáveis por um número alarmante de mortes nas grandes cidades" (op.cit.,p.2).

A localização geográfica de Santa Catarina confere uma predisposição deste espaço à exposição aos eventos extremos, tais como o clima subtropical úmido e o encontro de massas de ar com características térmicas diferenciadas. Essas adversidades atmosféricas, conforme Herrmann (2006), são características regional do espaço catarinense.

\footnotetext{
Os desastres naturais que ocorrem neste Estado referem-se às adversidades atmosféricas, caracterizadas pelos elevados totais pluviométricos, pelos prolongados meses de estiagem e pelas tempestades severas que frequentemente geram vendavais, granizos, tornados e marés de tempestades (HERRMAM et.al, 2009, p.1)
}

Conforme as autoras, no período de 1980 a 2007, o estado de SC foi afetado por 1229 ocorrências de inundações graduais, 701 de inundações bruscas, 140 de escorregamentos, destacando, no ano de 2004, o inédito episódio do Furacão Catarina.

Como outros estados da federação, as inundações graduais constituem-se nas principais ocorrências de desastres que afetam inúmeros municípios catarinenses

[...] durante o período considerado para análise dos desastres naturais (1980 a início de 2004) as inundações foram as responsáveis pelo maior número de desabrigados e mortos. Dentre os anos em que elas sucederam, destacam-se os de 1983 e 1984, que correspondem também aos anos em que foram registrados os maiores números de municípios atingidos pelas inundações" HERRMANN ( 2006 , p. 67).

O desastre de novembro de 2008 que atingiu seriamente o vale do rio Itajaí-Açu, além de vitimar um grande número de habitantes, desestruturou a economia regional pelos severos danos causados à infraestrutura, superando muito os episódios de inundações de 1983. 
Eventos extremos, como os que ocorreram durante o "El Niño" de 1983, apresentaram chuvas intensas e inundações (MARENGO, 2009) e afetaram seriamente várias regiões da América do Sul. Em Curitiba-PR, 200.000 pessoas ficaram desabrigadas (GEISSLER \& LOCH, 2004); em Santa Catarina, 90 municípios foram atingidos, totalizando 197.790 desabrigados e 49 mortos (os municípios mais atingidos foram: Blumenau, 50.000 desabrigados e 8 mortos; Itajaí, 40.000 desabrigados e 5 mortos e Rio do Sul, 25.000 pessoas desabrigadas) HERRMANN (2006). No estado do Rio Grande do Sul, conforme Reckziegel (2007, p.127-128), foram registrados, em 1983, 246 eventos adversos, “[...]162 estão associados à dinâmica fluvial, sendo 155 enchentes e 7 enxurradas; 83 estão associados à dinâmica atmosférica, sendo 63 vendavais e 20 vendavais acompanhados de precipitação de granizo; e 1 evento está associado à dinâmica de encosta, um deslizamento " (op.cit.).

Nos eventos recentes de 2008, é possível notar que houve um aumento nos danos causados pelos deslizamentos, fato esse que evidencia uma gestão ineficiente e que pouco aprendeu com os eventos passados, pois as encostas foram ocupadas em uma região onde os eventos pluviométricos de alta intensidade não são tão raros assim, hipótese, infelizmente, comprovada pela história recente de Santa Catarina.

Os eventos de inundação são recorrentes no tempo e historicamente afetam a rede urbana constituída ao longo do vale do rio itajaí. "No vale do Itajaí, Blumenau é a maior cidade da rede urbana, exercendo sua influência do litoral ao Alto Vale. No Baixo Vale ou Foz, Itajaí é a cidade pólo da micro-região; no Alto Vale é Rio do Sul "(SIEBERT, 2009, p. $44)$.

Os desastres ocorrem pela grande suscetibilidade natural da bacia do rio Itajaí-Açu, "A forma da bacia e a declividade dos cursos d'água que compõem a rede de drenagem contribuem significativamente para ocorrências de inundações" (AUMOND et al, 2009,p. 25).

Conforme os autores, do centro urbano de Blumenau até a foz do rio Itajaí, a declividade fica cerca de 0,013 (m/ $\mathrm{km})$. Com essas características do ambiente natural, o relevo plano, principalmente no trecho próximo à foz, é responsável pela formação de uma ampla planície, o que coloca essa região com elevada probabilidade de acontecer uma inundação, principalmente a partir de Blumenau (op.cit).

Nessa bacia hidrográfica, a planície de inundação foi lentamente sendo ocupada, o que faz com que a população conviva com inundações periódicas. Conforme Siebert (2009), a primeira grande cheia que atingiu Blumenau ocorreu em 1852, alcançando uma cota de 16,3 metros, dois anos após a fundação da colônia de Blumenau.

Conforme Aumond et al (2009), citando Frank (2003), entre os anos de 1852 a 2008, ao total, foram 69 eventos onde o pico da inundação ultrapassou a barreira da cota de 8,5 metros.

As grandes inundações de 1983 e 1984 afetaram cerca de 70\% da área urbanizada de Blumenau (SIEBERT, 2009). Uma forma de gestão do espaço urbano encontrada pelo poder público municipal foi instituir no Plano Diretor de Blumenau de 1989 a proibição de edificar ou aterrar abaixo da cota de 10 metros (op.cit).

Esse fato mudou o padrão de urbanização na cidade

As grandes enchentes levaram à verticalização das construções nas áreas inundáveis, em um novo modelo de urbanização para a classe média. Em Blumenau, bairros como Ponta Aguda e Vila Nova receberam, desde então, dezenas de edificações residenciais multifamiliares, a maioria com garagem e salão de festas 
nos primeiros andares, como forma de evitar que os apartamentos sejam atingidos por enchentes (SIEBERT, 2009, p.46).

Como o espaço urbano é o resultado da materialização das relações sociais, econômicas e de produção em um locus determinando que é a cidade, quando uma classe social, que detém condições econômicas de manter-se no mesmo lugar no espaço urbano, mesmo este apresentando uma alta suscetibilidade aos processos da dinâmica fluvial, consegue isso através da verticalização dos imóveis. Fica evidente que a parcela da sociedade que não detém as mesmas condições socieconômicas precisa encontrar um lugar para viver, ficando obrigada a ocupar as áreas disponíveis, especificamente na região do vale do Itajaí-Açu, essa ocupação foi orientada para as encostas.

Conforme Siebert (2009), o crescimento da cidade ilegal em Blumenau acompanhou o ritmo do crescimento populacional, fez com que a população de baixa renda, a qual, para fugir das enchentes literalmente, "ocupassem os morros" em um sistema de autoconstrução. Na maioria das vezes, em praticamente todas as cidades que enfrentam o problema do risco de deslizamentos, essas moradias são construídas de forma precária e sem nenhuma orientação técnica. Salvo exceções recentes, como o caso do programa Viva o Morro, que, através de uma ação entre agentes públicos e comunidade, visa orientar as melhores práticas construtivas para as áreas urbanizadas dos morros da Região Metropolitana do Recife.

Como em Blumenau o aumento no contingente populacional não foi acompanhado por uma igual oferta de programas habitacionais para a população de baixa renda, os migrantes que foram para a cidade "[...] encontraram na ilegalidade a alternativa mais viável para resolver seu problema de moradia" (SIEBERT, 2009, p.48).

A ocupação das vertentes íngremes do vale do Itajaí também foi realizada pela população de maior renda, que, fugindo das inundações, iniciou um processo perigoso de morar em áreas com grande declividade.

As particularidades do espaço geográfico catarinense, tanto em relação as suas caraterísticas geomorfológicas, principalmente da porção leste, associadas à dinâmica climática e ao uso e ocupação do solo, o tornam suscetível aos processos da dinâmica superficial. Embora os trabalhos de inventários sobre os desastres naturais remontem o final da década de 1990 e início dos anos 2000, os eventos recentes revelam que ainda há muito o que fazer com relação aos mecanismos de gestão e gerenciamento de riscos.

\section{Considerações Finais}

As situações de risco que atingem uma parcela significativa da população urbana brasileira representam o resultado de décadas de um processo de produção do espaço nas cidades marcado por uma intensa desigualdade de classe no acesso ao solo urbano. Este fato levou a ocupação de áreas sem as condições de habitabilidade, espaços ambientalmente frágeis da cidade e sem o interesse do setor imobiliário que controla o consumo e a produção do mercado formal de terras. $\mathrm{O}$ abandono por parte do Estado destas populações vulneráveis consolidou um processo de viver em risco que marca a paisagem dos centros urbanos do país, mais visível nas grandes aglomerações metropolitanas mas que é reproduzido em escala menor nas cidades de médio e pequeno porte. 
A geografia histórica dos desastres no Brasil comprova que apenas nas últimas décadas ações no sentido de gerenciar as áreas de risco começam a ser colocadas em prática em cidades como São Paulo, Rio de Janeiro, Belo Horizonte e Recife.

Projetos e programas associados ao gerenciamento de risco dão lugar às ações anteriormente prioritárias de agir após o desastre, fato que implicava em uma imobilidade por parte das comunidades atingidas e que acabava criando uma cultura assistencialista. A mudança que começa a ocorrer indica que a prevenção começa a ser prioritária no tratamento das áreas de risco no espaço urbano, e as comunidades inseridas no processo de construção de um espaço mais digno e seguro dentro da cidade.

\section{Referências}

ALHEIROS, M. M. Riscos de escorregamentos na região metropolitana do Recife. Tese de Doutorado em Geologia Ambiental . Universidade Federal da Bahia, 1998.

ALHEIROS, M. M.; SOUZA, M. A. A.; BITOUN, J.; GONÇALVES, E. M. \& MEDEIROS, S. M. G. M. (Coords). Diagnóstico Ambiental, Urbanístico e Social dos Morros - Programa Viva o Morro. . FUNDAÇÃO DE DESENVOLVIMENTO MUNICIPAL (Pernambuco), Recife. 2003. Disponível em: <http://www2.condepefidem.pe.gov.br/c/document library/get file?uuid=76543387-8a9c4121-bc9b-d1fa228af628\&groupId=19941> Acesso em: 13/01/2012.

AUGUSTO FILHO, O. Carta de riscos de escorregamentos: uma proposta método lógica e sua aplicação no município de Ilha Bela, SP. 1994. Dissertação (Mestrado em Engenharia de solos) - Escola Politécnica, Universidade de São Paulo, São Paulo.

AUMOND, J.J; SEVEGNANI, L; TACHINI, M \& BACCA, L. E. Condições naturais que tornam o vale do Itajaí sujeito aos desastres . In: FRANK, B. \& SEVEGNANI, L (Orgs) Desastre de 2008 no Vale do Itajaí. Água, gente e política. Blumenau: Agência de Água do Vale do Itajaí, 2009. p. 23-37.

BITAR, O. Y. Meio ambiente \& geologia. São Paulo: Editora Senac São Paulo, 2ª Ed. 2010.

CHAKARIAN, L. Uso e ocupação do solo urbano em encostas na área de proteção de mananciais da Bacia de Guarapiranga. 2008. Dissertação (Mestrado em Planejamento Urbano e Regional) - Faculdade de Arquitetura e Urbanismo, Universidade de São Paulo, São Paulo, 2008. Disponível em: <http://www.teses.usp.br/teses/disponiveis/16/16139/tde$\underline{12052010-155959 />\text {. }}$.

COELHO, M. C. N.. Impactos ambientais em áreas urbanas: teorias, conceitos e métodos de pesquisa. In: GUERRA, A. J. Teixeira; CUNHA, S. B. da. Impactos Ambientais Urbanos no Brasil. Rio de Janeiro: Bertrand Brasil, 2001. p. 19-46.

GEISSLER, H. J.; LOCH, R. E. N. Análise histórica das enchentes em Curitiba-PR: medidas propostas e conseqüências observadas. In: Anais...SIMPÓSIO BRASILEIRO DE DESASTRES NATURAIS, 1, 2004, Florianópolis. Florianópolis: GEDN/UFSC, 2004. p. 507523. (CD-ROM) 
HERRMANN, M. L de P. (org.). Atlas de Desastres Naturais do Estado de Santa Catarina. Florianópolis: $\quad$ IOESC, 2006.2 Disponível em:http://www.cfh.ufsc.br/ gedn/atlas/Atlas_Ceped.pdf. Acesso em: 20/01/2012.

HERRMANN, M. L. de P. ; CARDOZO, F. S. ; BAUZYS, Fernanda . Freqüência dos desastres naturais no estado de Santa Catarina no período de 1980 a 2007.. In: XII Encuentro de Geógrafos de América Latina, 2009, Montevideo - Uruguay, 2009, Uruguai. Anais do XII Encuentro de Geógrafos de América Latina, 2009., 2009. v. 1.

IPT - INSTITUTO DE PESQUISAS TECNOLÓGICAS . ACIDENTES ASSOCIADOS A MOVIMENTOS GRAVITACIONAIS DE MASSA OCORRIDOS NO MUNICÍPIO DE CAMPOS DO JORDÃO, SP: AÇÕES TÉCNICAS APÓS O DESASTRE. Publicação IPT 2815; São Paulo, 2002 .

Riscos atualizados em Santos. Disponível em: http://www.ipt.br/noticia/611.htm. 2012. Acesso em: 15/07/2013.

KOWARICK, L. Viver em risco: sobre a vulnerabilidade socioeconômica e civil. São Paulo: Ed. 34, 2009.

LAVELL, A. La gestión local del riesgo: nociones y precisiones en torno al concepto y la práctica. Guatemala: CEPREDENAC/PNUD, 2003. Disponível em: http://www.eird.org/encuentro/pdf/spa/doc15783/doc15783-contenido.pdf. Acesso em: 07/06/2011.

MARANDOLA JR., E. \& HOGAN, D. J. Natural hazards: o estudo geográfico dos riscos e perigos. Ambient. soc. [online]. 2004, vol.7, n.2, pp. 95-110. Disponível em: http://www.scielo.br/pdf/asoc/v7n2/24689.pdf. Acesso em: 20/03/2010.

MARENGO, J. A. Impactos de extremos relacionados com o tempo e o clima - Impactos sociais e econômicos. INPE. Boletim do Grupo de Pesquisa em Mudanças Climáticas GPMC. INPE-CCST-. Número 8 - Maio de 2009 - Edição Especial . Disponível em: $<$ http://mudancasclimaticas.cptec.inpe.br/ rmclima/pdfs/newsletters/Boletim No8 Port. pdf> Acesso em:10/01/2012.

MARQUES, E. C.; TORRES, H.; SARAIVA, C. Favelas no Município de São Paulo: estimativas de população para os anos de 1991, 1996 e 2000. Secretaria de Habitação do Município de São Paulo (SEHAB), 2003. Disponível em: http://www.centrodametropole.org.br/pdf/anpur2003_RBEUR.pdf. Acesso em: 12/01/2012.

MATTEDI, M. A.; FRANK, B. ; SEVEGNANI, L \& BOHN , N. O desastre se tornou rotina... In: FRANK, B. \& SEVEGNANI, L (Orgs) Desastre de 2008 no Vale do Itajaí. Água, gente e política. Blumenau: Agência de Água do Vale do Itajaí, 2009. p. 13-21.

MPSP. (Ministério Público do Estado de São Paulo). AUDIÊNCIA PÚBlICA SOBRE AÇÕES DE PREVENÇÃO E COMBATE AOS RISCOS E DANOS DECORRENTES DE CHUVAS EM ÁREAS DE RISCO NO MUNICÍPIO DE SANTOS. Disponível em: 
http://www.mpsp.mp.br/portal/page/portal/cao urbanismo e meio ambiente/Audiencias Publicas/Audiencia-Publica-Santos ATA (areas-risco-30-abr-2010).docx. 2010. Acesso em: 15/07/2013.

NOGUEIRA, F. R. GERENCIAMENTO DE RISCOS AMBIENTAIS ASSOCIADOS A ESCORREGAMENTOS: CONTRIBUIÇÃO ÀS POLÍTICAS PÚBLICAS MUNICIPAIS PARA ÁREAS DE OCUPAÇÃO SUBNORMAL. Tese de Doutorado. Universidade Estadual Paulista. 2002

NOGUEIRA, F.R. Gestão dos riscos nos Municípios. in: MINISTÉRIO DAS CIDADES. Prevenção de Riscos de Deslizamentos em Encostas: Guia para Elaboração de Políticas Municipais. Brasília: Ministérios das Cidades/Cities Alliance, 2006.

OGURA, A. T.; SILVA, F. C.; VIEIRA, A. J. N. L. Zoneamento de risco de escorregamento das encostas ocupadas por vilas operárias como subsídio à elaboração do plano de gerenciamento de áreas de risco da estância climática de Campos do Jordão - SP. In: SIMPÓSIO BRASILEIRO DE DESASTRES NATURAIS, 1., 2004, Florianópolis. Anais... Florianópolis: GEDN/UFSC, 2004. p. 44-58. (CD-ROM)

PASTERNAK, S \& BOGUS, L. M. M. Moradia e segregação na cidade de São Paulo. Territorios (Bogotá), Bogotá, v. 12, p. 79-107, 2004.

PEREIRA, C. V. L. Estudo de caso: O programa de áreas de risco em Belo Horizonte. In: $\mathbf{2}^{\mathbf{0}}$ SIBRADEN - Simpósio Brasileiro de Desastres Naturais e Tecnólogicos. 09 a 13 de dezembro: Santos - $\quad$ SP. 2007. Disponível em: http://www.acquacon.com.br/2sibraden/palestras.html. Acesso em: 22/07/2012.

PRADO, O. . Parcerias nos Morros. In: Marco Antônio Carvalho Teixeira; Melissa G. de Godoy; Roberta Clemente. (Org.). 20 experiências de Gestão Pública e Cidadania. 1 ed. São Paulo: Programa Gestão Pública e Cidadania, 2006, v. 1, p. 137-144.

PREFEITURA DE SÃo PAUlO. Áreas de Risco. São Paulo, s/d. Disponível em:<http://www3.prefeitura.sp.gov.br/saffor bueiros/FormsPublic/serv14AreasRisco.aspx>. Acesso em 9/01/2012.

. LEI ORGÂNICA DO MUNICÍPIO DE SÃO PAULO (Atualizada até a Emenda no 34, de 27/4/2011) , 1990. disponível em:< http://www.tcm.sp.gov.br/legislacao/lomun/LOMSP2011.pdf>. Acesso em: 10/01/2012

.. Áreas de Risco. São Paulo, 2011. Disponível em:<http://www3.prefeitura.sp.gov.br/saffor bueiros/Image/Areas de Risco 2010.pdf> Acesso em 12/01/2012.

PRUDENTE, C. N. \& REIS, R. J. . Banco de Dados de Desastres Naturais em Belo Horizonte 1979 a 2009. In: Anais... Xlll Simpósio Brasileiro de Geografia Física, 2009, Viçosa. Xlll Simpósio Brasileiro de Geografia Física, 2009. 
REBELO, F. Um novo olhar sobre os riscos? O exemplo das cheias rápidas (flash floods) em domínio mediterrâneo. 2008, Territorium, 15, p. 7-14

RECKZIEGEL, B. W. Levantamento dos desastres desencadeados por eventos naturais adversos no Estado do Rio Grande do Sul no período e 1980 a 2005. 2007. 261p. Vol.I. Dissertação de mestrado em Geografia. Universidade Federal de Santa Maria, Santa Maria, 2007.

REIS R. J. Dos; GUIMARÃES, D. P; COElHO, C. W. G. A.; PAIXÃO, G. M da; NASCIMENTO, J. S. de \& SIMÕES, T. K. de S. L. Determinação das áreas de potencial de riscos de precipitações intensas em belo horizonte. Caderno de Geografia, Belo Horizonte, V. $14, \quad$ N. 23, P. 127-134, 2º Sem. $2004 . \quad$ Disponível em: $<$ http://www1.pucminas.br/documentos/geografia 23 art08.pdf?PHPSESSID=de218b62f 4bb0ba9538e9215bd0d1765> Acesso em: 12/01/2012.

SEHAB-SP. Programa de Urbanização de Favelas da Cidade de São Paulo. In: Prefeitura Municipal de São Paulo. A Cidade informal no Século XXI. Prefeitura Municipal de São Paulo, SEHAB - Superintendência de Habitação Popular, 2ª ed. 2010. p. 10-11. Disponível em: $<$ http://www.habisp.inf.br/theke/documentos/publicacoes/catalogo exposicao/index.html >. Acesso em: 10/01/2012.

SIEBERT, C. (Des)controle urbano no vale do Itajaí . In: FRANK, B. \& SEVEGNANI, L (Orgs) Desastre de 2008 no Vale do Itajaí. Água, gente e política. Blumenau: Agência de Água do Vale do Itajaí, 2009. p.39-51

SOUZA, M. L. de. Mudar a cidade: uma introdução crítica ao planejamento e à gestão urbanos. Rio de Janeiro: Bertand Brasil, 2004.

SOUZA, M. L. de \& RODRIGUES, G. B. Planejamento urbano e ativismos sociais. São Paulo: UNESP, 2004 (Coleção Paradidáticos; Série sociedade, espaço e tempo).

TASCHNER, S. Degradação ambiental em favelas. In: TORRES, H.G. E COSTA, H. População e Meio Ambiente: debates e desafios. São Paulo: Editora do Senac, p. 241- 300, 2000.

UNISDR. Terminología sobre Reducción del Riesgo de Desastres. Ginebra, Suiza: UN, 2009. Disponível em: http://unisdr.org/files/7817 UNISDRTerminologySpanish.pdf. Acesso em 12/04/2011.

WALDHEIM , P. V. Sistema Alerta Rio /GEORIO. Disponível em: www.rioperacional.ufrj.br/apresentacoes/ALERTA-RIO.pdf. 2006. Acesso em: 06/01/2012 